\title{
Patient's Cross-border Mobility Directive: Application, Performance and Perceptions Two Years after Transposition
}

\author{
Rafał Riedel \\ Institute for European Studies, \\ Chemnitz University of Technology, Germany \\ Opole University \\ ul. Katowicka 89 , \\ Opole 45-061, Poland \\ E-mail: riedelr@icloud.com
}

\begin{abstract}
This paper seeks to analyse the directive on the application of patients' rights in cross-border healthcare. Two years after the transposition, it is time for first evaluations of its application, performance and perception. The analysis consists of three major elements: reconstruction of the legal scope and subject matter of the new legislation, conclusions of the evaluative reports monitoring its implementation and performance as well as the public opinion polls revealing the EU citizens' perception of its details. These three components combined together deliver a picture of the state of play about the pan-European cross-border patients'mobility. The bottomline conclusions negatively verify the supposition present in some earlier literature on patients' cross-border mobility that the directive has a transformative potential leading towards the creation of truly competitive pan-European medical market. After two years of its operation, there is still no increased patients' mobility across EU internal borders observed. As regards the speculations for the future, there are only some weak symptoms identified and they may result in intensified cross-border mobility for healthcare.
\end{abstract}

Keywords: cross-border healthcare, directive, patients' mobility 


\section{Introduction}

Directive on the Application of Patients' Rights in Cross-border Healthcare (EC, 2011), commonly known as the Patients' Mobility Directive ${ }^{1}$ carries a lot of potential. Originally designed to supplement the famous 'Service Directive'2, it frames the legal scope conditions for the trans-border service provision in the field of healthcare. This is a sector of economy which transfers several times the amount of the EU budget itself. But the Directive's potential impact may go far beyond the framing of patients' rights outside of his/her country of origin. In the process of time, its mechanisms may lead to the harmonisation of healthcare systems across Europe and even be the founding stones for the truly competitive European medical market. The objective of the paper is to capture the functioning of the directive four years after concluding its legislation and two years after its transposition. By combining three streams of data - the legal scope and subject matter of the directive implemented, the conclusions from the evaluative reports monitoring its implementation and performance as well as the public opinion polls revealing the EU citizens' perception of its details - this analysis will give a picture of the state of play about the pan-European crossborder patients' mobility as it was in 2015 .

After two years of the Directive's functioning, the first reports appeared evaluating its performance. Some of them forced by the act itself, some of them from the initiative of various stakeholders - patients, medical personnel, authorities, and others. Their conclusions - even though formulated in a relatively short time perspective - are highly indicative since they offer suggestions and recommendations in a critical time of the Directive's application time. They will be confronted with the Directive's goals and objectives as well as with the public opinion on the topic in this analysis. The extensive descriptions of the content of the Directive (which itself is quite a large document, especially together with the analysis and reports commissioned by the EU) is targeted at the precise reconstructions of the scope of this piece of legislation. Apart of the descriptive function, the paper also has some exploratory ambitions, reading the

1 Sometimes it is also known as the 'waiting time directive' since its application is the most common in times of undue delay in providing the medical services by the healthcare system of the country of origin. It entitles patients to reimbursement for treatments (when they are subject to prior authorisation but most hospital treatments are) that cannot be provided within a reasonable time in the Member State of affiliation (Peeters, 2012).

2 The political impulse for legislating the Directive on patients mobility emerged in the process of works on the Service Directive (2006/123). Healthcare was excluded from the Service Directive as a specific sector which needs separate legal framing. 
directive into the context of the pan-European healthcare market conditions and its potential change. It makes some assumptions (based on the legal text and the intentions of the legislator) and verifies them in the light of the available data. In the conclusive part, the author formulates some speculative statements regarding the future evolution paths of the cross-border healthcare provisions. Methodologically speaking, the paper interprets the legal text of the Directive and confronts it with the situation, conditions and circumstances on the pan-European healthcare market. Subsequently it also confronts the expectations related with the new legislative act with real-life developments on the ground, two years after its transposition. The author extracts from the available data on the application of the Directive's provisions with special attention dedicated to the patients' behaviour and their opinions formulated in the polls. The article positions itself in the broad stream of literature dedicated to the Europeanisation phenomenon (Wallace, 1971; Risse-Kappen, 2001), explaining the impulses of Europeanisation and their transformative potential in a specific, medical, sector (Riedel, 2016).

The structure of the paper proceeds as follows: after a short introduction into the theme of pan-European medical services market, the analysis focuses on the directive dedicated to the European patients' cross-border mobility directive, then consequently it evaluates its application and performance. This part of analysis is based on a number of reports commissioned by the EU itself or published by independent bodies. This naturally leads to the issue of perceptions-how this Directive is seen by the Europeans and the European patients who had the opportunity to benefit from it in the time span of two years after its legal implementation.

If we look at the European Union as it is today, it is clear that there is an increasing mobility across the continent. EU citizens are moving to work, study, tourist travel or for any other reason between and across other Member States, which raises the question of social security coverage and access to healthcare in the host country (Hartley, 2010). Mobility of persons in general, and patients in particular, constitutes one of the four cornerstones of the Internal Market, commonly called 'the four freedoms' (Sieveking, 2007). Contrary to this, the health systems of EU Member States have been organised around the principle of territoriality. In practical terms it means that the EU citizens are restricted to using the public health services located in their state of residence ${ }^{3}$. At the same

3 Beyond this common principle, EU health systems are, by and large, separated into two main models. The first is based on a system of universal coverage of health service provision which is free at the point of delivery and which is funded through general taxation. The second model is a social insurance system, under which insurance payments are made to sickness insurance funds, which then fund treatment. 
time, according to Article 152(5) of the EC Treaty, "Community action in the field of public health shall fully respect the responsibilities of the Member States for the organisation and delivery of health services and medical care" (Hunt \& Wallace, 2006). The development of healthcare legislation in Europe took place as an interaction between national experts and scholars, and initiatives taken by international organisations such as the World Health Organisation, the Council of Europe and the European Economic Community (later the EU). Legal developments at national levels interacted with the initiatives taken by the international community, which in turn worked as a source of inspiration for further national developments (Hartley, 2010). In the beginning, it was the WHO's European regional office in Copenhagen that played a significant role in both instigating surveys and comparative studies, as well as bringing national experts together. Among other things, this resulted in the European Declaration of the Rights of Patients of 1994 (Hartley, 2010; Riedel, 2015). However, the most important role in this sphere was played by the EEC/EU which have also increasingly influenced the development of health law in Europe in respect of both regulatory measures and as a result of the European Court of Justice judgements.

\section{The Directive's subject matter and scope}

As indicated above, the four freedoms principle implies the right to offer, and to receive, services across national borders within the territory of the EU. 'Services' are defined in Article 50 of the EC Treaty as activities of an industrial character, activities of a commercial character, activities of craftsmen and activities of the professions, which are normally provided for remuneration. Additionally, according to Article 49 of the EC Treaty, restrictions on the cross-border provision of services are prohibited. This also gives expression to the general principle of EU law of non-discrimination on the grounds of nationality (Hunt \& Wallace, 2006). The legal basis of the Directive is laid out in Articles 114 and 168 of the Treaty on the Functioning of the European Union (TFEU), stating that "a high level of human health protection is to be ensured in the definition and implementation of all Union policies and activities" (Art. $168(1)$ ). Union legislation has to rely on this legal basis even when public health protection is a decisive factor in the choices made (Art. 114) and achieving harmonisation, a high level of protection of human health is to be guaranteed (Art. 114(3)). According to Article 152 of the Treaty of the European Union (TEU), the Union should ensure a high level of human health protection in the 
definition and implementation of all Community policies and activities, and that it must furthermore complement national policies regarding public health measures. However, it is also stipulated that "Community action in the field of public health shall fully respect the responsibilities of the Member States for the organisation and delivery of health services and medical care" (Hartley, 2010).

The subject matter and scope of the Directive is expressed in Article 1 of Chapter 1 ('General Provisions') and is formulated in the following way: "This Directive provides rules for facilitating the access to safe and high-quality crossborder healthcare and promotes cooperation on healthcare between Member States, in full respect of national competencies in organising and delivering healthcare." The Directive applies to individual patients who decide to seek healthcare in a Member State other than the Member State of affiliation. 'Crossborder healthcare' in this Directive means 'healthcare provided or pre-scribed in a Member State other than the Member State of affiliation' (Article 3e). The Directive concerns thus patient mobility: the patient receives medical care (or buys medicines or medical devices) in another Member State than the one in which he is socially insured (Peeters, 2012). The Directive applies to the provision of healthcare to patients, regardless of how it is organized, delivered and financed. However at the same time, it does not affect the regulations of the Member States relating to the organisation and financing of healthcare in situations not related to cross-border healthcare.

As it was indicated by the Health Commissioner, Tonio Borg, in his statement on the entry into force of the Directive:

For patients, this Directive means empowerment: greater choice of healthcare, more information, easier recognition of prescriptions across borders. The Directive is also good news for Europe's health systems, improving cooperation between Member States on interoperable eHealth tools, the use of health technology assessment, and the pooling of rare expertise (EC, 2013).

Article 3 of the Directive provides important definitions. 'Healthcare' is defined as health services provided by health professionals to patients to assess, maintain or restore their state of health, including the prescription, dispensation and provision of medicinal products and medical devices (Art. 3a). 'Member State of affiliation' means: the Member State that is competent to grant to the insured person prior authorisation to receive appropriate treatment outside the Member State of residence (Art. 3c). And 'Member State of treatment' means the Member State on whose territory healthcare is actually provided to the 
patient (Art. 3d). The heart of the Directive places itself in Article 5, which states that the Member State of affiliation shall ensure that the cost of crossborder healthcare is reimbursed ${ }^{4}$ (Art. 5a) and it is the responsibility of the Member States to establish mechanisms in place to provide patients on request with information on their rights and entitlements in that Member State relating to receiving cross-border healthcare.

The following articles of the Directive focus on cross-border cooperation in healthcare. They touch upon the mutual assistance in implementation of the Directive, European reference networks, eHealth or cooperation in the case of rare diseases as well as health technology assessment. However they also deal with other practical issues, like for example the recognition of prescriptions issued in another Member State (another from the country of affiliation). In the final articles, the transposition time was set up on the date of 25 October 2013 (Art. 21) and the Commission was obliged to prepare a report no later than 25 October 2015 and subsequently every three years thereafter (report on the operation of the Directive) and submit it to the European Parliament and the Council (Art. 20).

The Directive respects and is without prejudice to the freedom of each Member State to decide what type of healthcare it considers appropriate. This means that it is for the home state to decide, whether at local, regional or national level, what healthcare benefits a patient is entitled to, regardless of whether the patient is treated in his home state or across borders. Therefore the obligation to reimburse costs of cross-border healthcare should be limited to healthcare to which the insured person is entitled according to the legislation of the Member State of affiliation. The applicable reimbursement tariff is that of the Member State of affiliation. This implies that the healthcare treatment should be reimbursable in the Member State of affiliation. If not, the reimbursement tariff is $0 €$. The reimbursement, however, can not exceed the actual costs. Member States can decide (and are thus not obliged to do so) to reimburse the full costs in case these costs exceed the reimbursement tariff reimbursement in the Member State of affiliation (Art. 7.4). Additionally, the Directive excludes the following from the scope of its impact:

- organ transplantations

- $\quad$ public vaccination programs

- long-term care (supporting people in need of assistance in everyday routine tasks).

4 However, the Member States of affiliation are allowed to provide a system of prior authorisation for reimbursement of costs of cross-border healthcare. 


\section{Application and performance}

Following Article 20 of the Directive, the Commission was obliged to prepare a report no later than 25 October 2015 (and subsequently every three years thereafter) on the operation of the Directive and submit it to the European Parliament and the Council. In 2015, this report was prepared much earlier. It was also accompanied by many other reports monitoring the implementation and performance of the Directive. Here, the focus will be on two reports: Evaluative Study on the Cross-border Healthcare Directive (2011/24/EU) (EC, 2015a) and Summary Report: Cross-border Healthcare: Main Conclusions and Recommendations Arising from the EPF Series of Regional Conferences 2013-2014 (EPF, 2015). Methodologically, the analysed reports were quite diversified. The methods of collecting and processing the data included desk research, web site analysis, online surveys, and qualitative interviews. They embraced the patients, healthcare providers, medical personnel, labour unions, ombudspersons, healthcare inspectorates and other stakeholders. Additionally, a pseudo patient investigation exercise (in order to understand the operational functioning of the Directive) was applied.

The first report-Evaluative Study on the Cross-border Healthcare Directiveis much more optimistic in its conclusions (it is important to note that it was prepared on behalf of the EU Commission) and summarises that no specific problems were identified with the reimbursement procedures. However, the reports says, it should be kept in mind that an increase in patient numbers seeking cross-border care may reveal unforeseen concerns (EC, 2015a). So far, there is not much mobility but there is quite a number of requests addressed by the patients to the National Contact Points (that were established in the Member States based on the Directive regulations). Even though the personnel of these NCP is rather modest (from one to three persons on average), they receive sometimes more than a hundred requests per month from the potential crossborder patients. This may suggest that the interest in this type of healthcare is potentially quite high. The exact figures are shown in Figure 1.

Access to information is very important in the case of implementation of this Directive as the second report-Summary Report: Cross-border Healthcareforecasts that the improvement of cross-border mobility is conditional on the patient's knowledge about their rights and stemming from them benefits. Those informed, however, see the Directive as offering opportunities to enable patients exercise their rights, among which are faster access to treatments for patients experiencing long waiting times, increasing the transparency of providers and 
pricing of medical procedures, forcing the national healthcare providers to improve their performance. At the same time, a number of shortcomings of the new legal situation was identified, including the problem of paying for the costs upfront, determining what constitutes undue delay, the most affluent and bestinformed patients benefiting the most, which generates worsening of existing health inequalities (EPF, 2015).

Figure 1. Frequency of patients' requests for information from NCP

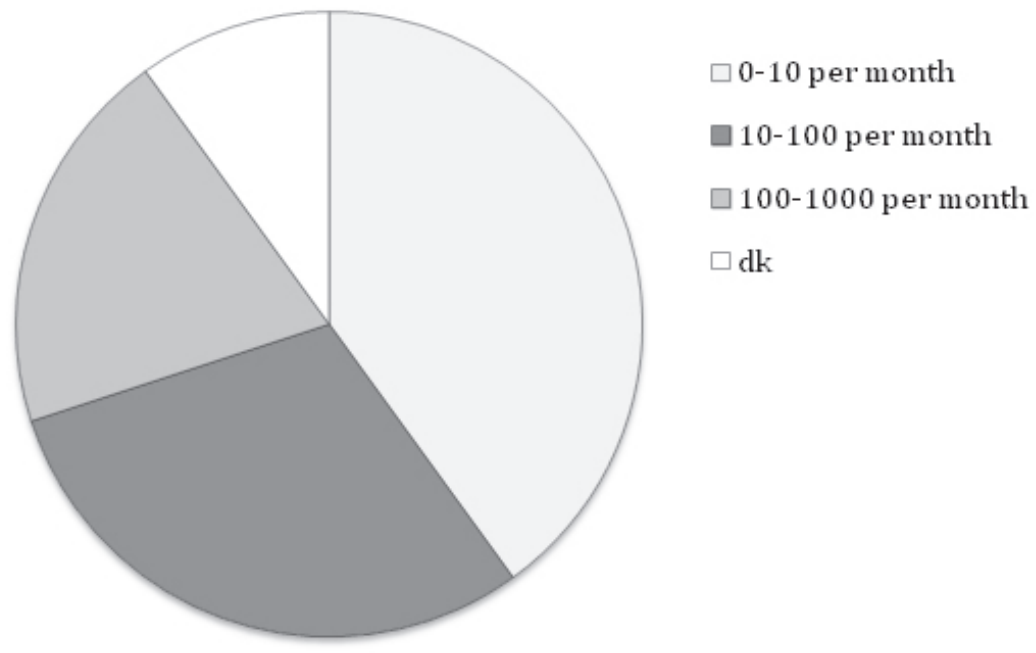

Source: Based on the data in EC, 2015a

Figure 2 shows some data on the NCP websites which contain information on patients' rights.

The waiting times (which are one of the most frequent reasons to look for crossborder healthcare options) differ widely across the Member States; however, it important to note that the waiting times differ also substantially within one Member State or even within one city. For example, the waiting time for a cataract surgery is 34 days in the Netherlands, 84 days in Portugal, and 114 days in Finland. At the same time, the waiting times for the head tomography vary considerably within the scale of one city-in District XI of Rome, for instance, the patient waits for this diagnostic treatment for 10 days, whereas in District I the waiting time is 71 days (EC, 2015a). Different approaches are being employed by the authorities of the Member States of affiliation as regards the patients' entitlements in case of waiting time not considered medically justifiable. Local insurers usually provide assistance to patients in finding hospitals that can 
Figure 2. NCP websites which contain information on patients' rights

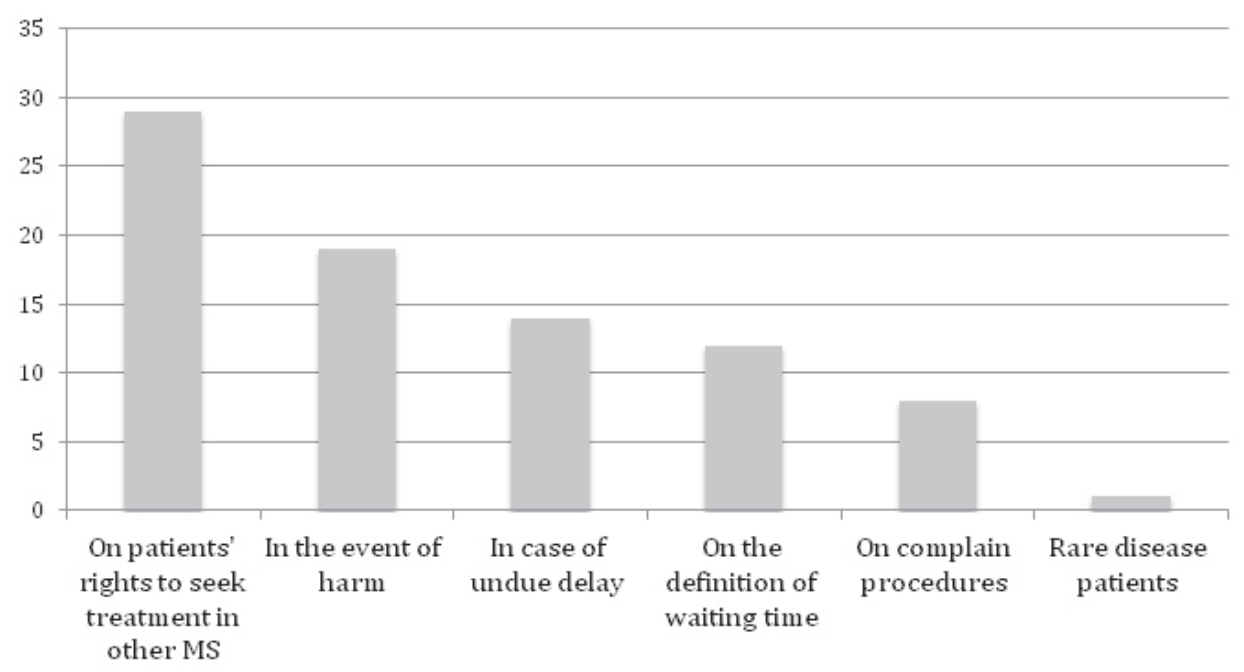

Source: Based on the data in EC, 2015a

treat patients in due time within the Member States (for example, at private healthcare providers). Some other difficulties with implementing the Directive are connected with the technicalities of the medical sector. In different Member States, various and diversifying clinical guidelines are applied. There is a need identified for more convergence among the different healthcare systems in terms of guidelines, procedures and quality. Another barrier was spotted in the subject of medical records - standards regarding access to them (even by the patients themselves) still vary across the EU. The Directive improved access to healthcare on a marginal scale, only among these patients who are informed and aware of their rights. And, which is critically important, only among the ones who can afford the up-front payment for often costly medical service abroad. In some countries (for example, in Sweden) the last problem was partially resolved by offering the financially handicapped patients some assistance in the form of a special procedure which did not require up-front payments. The Summary Report: Cross-border Healthcare evaluates the functioning of the Directive at different stages of the cross-border mobility, including the: 'decision-making' stage, 'before leaving' phase, 'during the stay' phase and finally 'after returning home' stage. At the 'decision-making' stage the most frequently mentioned considerations were:

- Finding out about the treatment options available (at home and abroad),

- Information on waiting lists,

- The process of getting decision on reimbursement, 
- Information about the safety and quality of the service and providers,

- Information on the clinical guidelines in various Member States,

- The language capacities of health providers,

- Safety risks (for example, infections),

- Protection / transfer of medical data.

At the 'before leaving' stage, the following the following issues appeared to be problematic:

- The documents required in a healthcare system abroad,

- Medical files accurately translated and transferred,

- Logistical matters (also for accompanying persons),

- Financial schemes,

- Information about the patients' rights in the healthcare system serving the treatment.

The 'during the stay' phase was marked by the following considerations:

- Common (by the patient and the medical team) understanding of the treatment process,

- Unforeseen events (for example, complications extending the term of hospitalisation),

- Unexpected additional costs,

- Language and cultural communication issues,

- Discrimination by the medical personnel (for example, on the grounds of being classified as "health tourist" occupying the place instead of some local patient).

The most common concerns in the 'after returning home' phase were the following:

- Delays in reimbursements of costs,

- Complex administrative procedures,

- Obtaining the prescribed medicines,

- Rehabilitation concerns,

- Necessity to repeat the treatment,

- Side-effects and complications,

- Knowing how to complain in case of arising problems arising. (EPF, 2015, pp. 8-9)

The reports define the state of play in the trans-border healthcare in Europe and conclude that the legislative initiative at the EU level stimulated genuine reformist efforts in many EU member countries enabling improved transparency 
and patients' mobility as well as progress in health technology assessment, eHealth cooperation and European reference networks. The citizens' awareness, however, remains at the relatively low levels in most analysed countries. They are not informed properly, most of them do not realise the existence of such possibilities, or do not recognise the National Contact Points that were established. The new legal provisions do not limit themselves to entitling patients to cross-border public healthcare, but they benefit patients in many other ways. Access to information on healthcare possibilities in another EU Member State is better (and this increases the medical treatment options). They create a framework for health authorities to cooperate more closely in the field of quality and safety standards in healthcare.

\section{Perceptions}

Most EU citizens do not have much experience with cross-border healthcare. Those who have travelled to another EU Member State (or wider European Economic Area and Switzerland) are familiar with the E111 form (or its successor, the European Health Insurance Card). This system entitles those temporarily present in another Member State, whether for travel, study, or to seek employment, to exclusively emergency health treatment if they fall ill or have an accident whilst abroad (Hunt \& Wallace, 2006). The Directive on the application of patients' rights in cross-border healthcare changes the rules of the game in legal terms. However, in terms of the Europeans' perceptions not much has changed in this regard. Special Eurobarometer 425, entitled Patients'Rights in Cross-border Healthcare in the European Union (EC, 2015b) was dedicated to this issue. It was designed to explore how many Europeans have received medical treatment in another Member State, to understand how willing they would be to do so, what they would see as the strongest benefits or barriers, and to check what knowledge they have about the issue.

Around half of the European Union population (53\% in 2007 and $49 \%$ in 2015) showed some interest and willingness to receive medical treatment in another Member State (usually coming from the smaller countries, such as Malta, Luxemburg or Cyprus). However, only five per cent had had such an experience in the past. A large majority of them confirmed not having any problems with the reimbursement. The motivations behind the willingness to travel to another country vary from one Member State to another. The cumulated EU-wide results are presented in Figure 3 below. 
Figure 3. For which of the following reasons would you be willing to travel to another EU country to receive medical treatment?

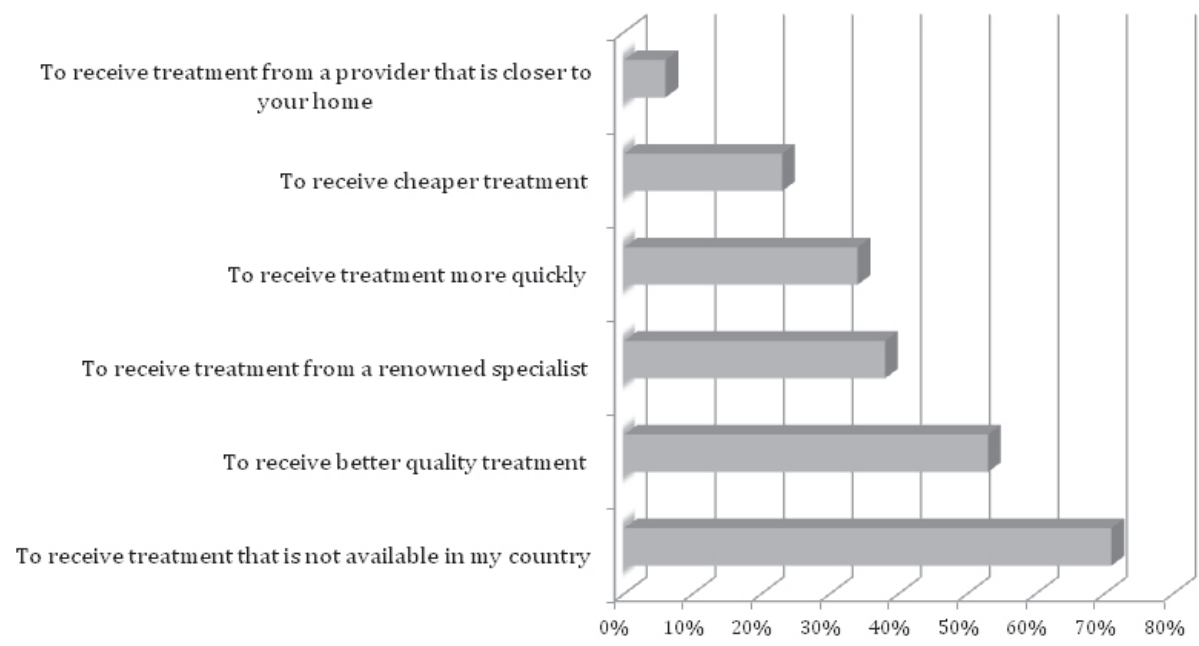

Source: EC, $2015 b$

In 26 out of $28 \mathrm{EU}$ Member States, the main reason stated by the respondents was to receive treatment that is not available in the country of insurance. Only in Bulgaria and Lithuania the most popular answer was: "to receive better quality treatment". Price (the answer "To receive cheaper treatment") was mentioned predominantly in the more "expensive" healthcare systems (such as Germany, Finland, Austria) and only marginally in these countries where medical services are at the relatively lower levels (such as Malta, Spain or Bulgaria). From a socio-demographic perspective, no strong differences were revealed, however some tendencies could be observed. Respondents motivated by better quality treatment are usually younger and more educated, whereas receiving more affordable treatment was mentioned more by manual labourers than by any other occupational category. Among the reasons for which the EU citizens are unwilling to receive cross-border healthcare, the Eurobarometer study shows the following results: 
Figure 4. For which of the following reasons are you unwilling to go to another EU country to receive medical treatment?

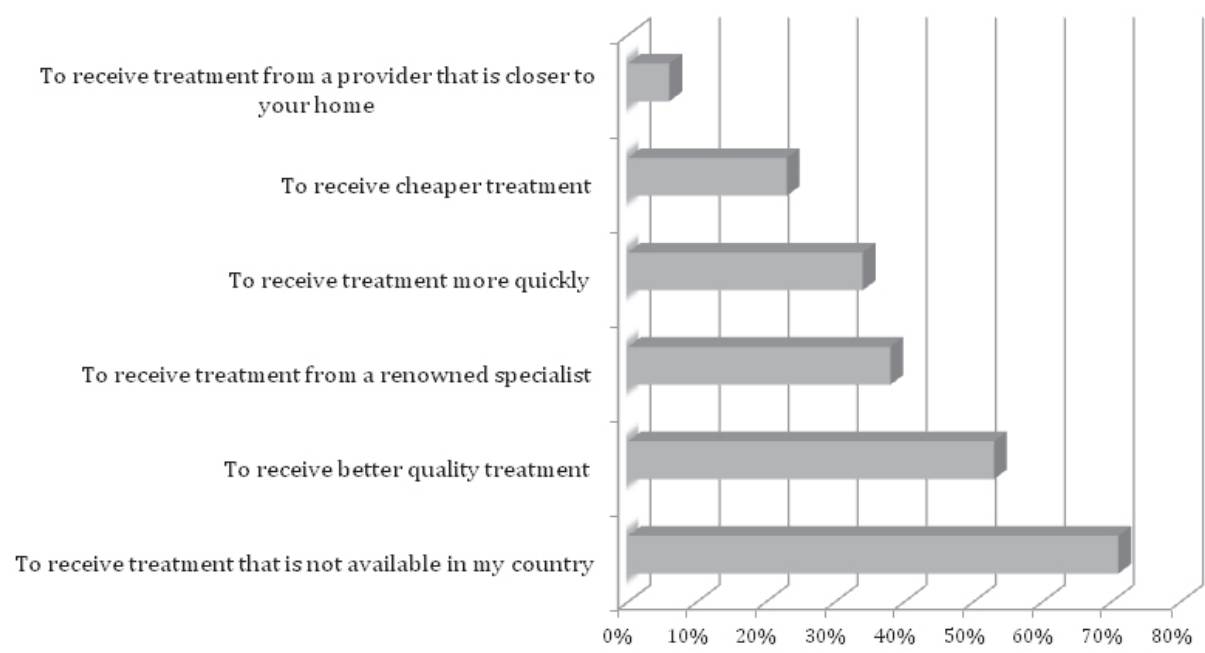

Source: EC, $2015 b$

The above-presented data demonstrates that receiving medical treatment at home (which they are satisfied with) is considered by most Europeans as the safest and the most convenient option. Concerns about the quality of medical treatment were expressed by 21 per cent of these respondents who at the same time felt they did not have enough information and awareness about the availability and quality of the medical service abroad. Not surprisingly, the EU citizens using the healthcare systems with the best reputation (such as Finland, Luxembourg, Sweden, Austria) are satisfied with the medical offer and gave it as a reason for not taking cross-border medical treatments. Whereas potential patients from Poland and Bulgaria, having a rather low quality perception about their healthcare systems, do not state this reason as frequently. Age seems important in case of the "language issue". Potential problems with understanding the foreign language was much more often mentioned by people aged 55 and older. The same applies to people with lower education, old-age pensioners and housepersons. In terms of access to information, the situation is the other way around - here the problem was much more often identified by students, white collar workers, than by housepersons, the retired or the unemployed.

The bottom-line conclusion from the opinion poll data is that cross-border healthcare did not change as a result of the Directive on the application of patients' rights in cross-border healthcare. The Eurobarometer data from 2007 and 2015 remain very similar on key issues. Only 1 per cent increase is observed 
in the cross-border healthcare experience (from 4\% in 2007 to 5\% in 2015). Due to the fact that the majority of these experiences are urgent situations, one may conclude that they were not these medical situations that the Directive was dedicated to. Compared to 2007 there is even a decrease in the number of respondents who would be willing to go abroad to seek medical treatment. Also, most EU citizens do not feel well informed about the types of healthcare they are entitled to, their rights abroad and reimbursement procedures.

\section{Conclusions}

The Directive on the application of patients' rights in cross-border healthcare is complementary to the Service Directive and the natural consequence of the free movement of persons principle. The logic behind the Directive was hidden in a supposition that the growing mobility of EU citizens will be accompanied with the growing cross-border medical service provision. This has not happened so far; however, the patients' mobility and cross-border medical care are still significant issues of the actual discussion about the future development of the healthcare systems of the Member States of the European Union and the potential of the Europe-wide medical market.

Contrary to the relatively moderate competence in the area of health, it appears that the EU has influenced this sector through a number of different regulatory initiatives. In certain policy areas, such as medical trials, data protection, and pharmaceuticals, EU legislation and regulations provide common standards and give patients rights which may exceed those afforded by domestic rules (Hartley, 2010). The initial rights for patients were defined by the Communities establishing treaties (subsequently, for example, in Regulation (EEC) 1408/71 on the social security of migrant workers) and later in the judgements of the European Court of Justice. The Court's rulings provoked considerable effects in national governments, insurance institutions, care providers, medical professionals, and patients' attitudes (Sieveking, 2007). The EU legislation affects, in the process of Europeanisation, national health policies both directly and indirectly through a variety of instruments. A number of regulations and directives in areas such as the movement of medical professionals and social security are specifically dedicated to the healthcare sector. The Directive on the application of patients' rights in cross-border healthcare is further steps ahead, stating that if treatment abroad falls within the healthcare package of the patient's state of residence, the patient is entitled to the same reimbursement 
of costs ${ }^{5}$ as if treatment had been provided in the state of residence (Hartley, 2010). The Directive contains provisions concerning the reimbursement of costs, the responsibilities of the Member States' healthcare systems and their mutual cooperation. Analysing the potential impact of Directive 2011/24 on EU healthcare systems, patients and healthcare providers, it becomes clear that the impact of the directives may reach far beyond the patients' mobility. The Directive establishes patients' rights, pays attention to the quality and safety of healthcare services, and creates an excessive framework of cooperation in the field of healthcare (Peeters, 2012).

However, this analysis admits that the patient flows between Member States are limited and expected to remain so, as the vast majority of patients in the EU receive healthcare in their own country, and they prefer to do so. The Directive did not stimulate cross-border patients' mobility within the EU or EEA (plus Switzerland). The bottom line conclusions refer to the intensity of patient mobility - which remains at very low levels. Only about one per cent of public spending on healthcare goes on cross-border healthcare (approximately 10 bln euros), including emergence care for tourists (EC, 2013). There is not much mobility of European patients (apart from tourism-related emergency cross-border medical treatments). Proportionally, there is actually much more mobility among the medical personnel then among the patients. The issue itself raises important ethical questions since recruitment of in the medical sector (especially doctors and nurses) happens usually from predominantly low- and middle-income to high-income states.

A number of barriers which cannot be removed by legal acts are still present on the European Single Market. Even such things as language or cultural communication issues may act as an effective barrier. Apart from that, also the following concerns can be identified: logistics, translation and circulation of documents, and - last but not least—finances. Part of the cross-border mobility is also filled with migrants traveling to their former country of origin to receive medical treatments. An exemplification of this phenomenon is provided in a study conducted between 2008 and 2011 on Polish women who migrated to London, Barcelona, and Berlin (Main, 2014). It concludes that the principal reasons for medical travel to Poland are the lower cost of private medical treatment, relatively easy access to specialised health care, and personal comfort derived from linguistic and cultural competency (Main, 2014). However, there is some modest willingness to get medical treatment abroad - and it is important to note that it is lower than before the Directive was legislated and implemented.

5 However, in case of hospital care the patient is required to seek prior authorisation. 
A vast majority of Europeans prefer to receive their medical treatment at home. However, the large number of requests to the National Contact Points show some potential for the future cross-border healthcare mobility. Especially since access to cross-border healthcare is conditional on the knowledge and access to information about the waiting times, options at home and abroad, and simplicity of procedures.

The analysed Directive may be a founding stone of truly pan-European healthcare market - however, now only theoretically since the first years of development do not entitle to claim so. When it comes to the organisation of healthcare sectors and attitudes to basic patients' rights, there are vast differences among the EU members. Consequently, at the European level, health law has to balance between the aspiration for uniformity and universal respect for fundamental rights on the one hand, and acceptance of national diversity on the other (Hartley, 2010). The variations amongst EU Member States show that the Directive has some reformist potential - especially in the Member States with lower medical standards (such as Bulgaria or Poland). Potential patients from these states show much more interest and willingness to travel abroad to receive better quality treatment. This may act as a stimulus for a move towards equalisation of the healthcare standards across Europe by forcing the local providers to improve their performance (Toller, 2010). On the other hand, this Directive may have some potential for deepening inequality in access to healthcare. Cross-border medical service provision is designed for those who are better informed and with the financial possibilities of up-front funding. Therefore, in practical terms, it excludes a large portion of EU citizens who simply cannot afford it or do not have enough linguistic capacities. These social and the economic aspects of the social security system, especially in the health sector, are of great importance for the welfare of the citizens. It shows in quite a sharp contrast that the EU suffers in some public policies (here exemplified by the healthcare) a kind of a structural asymmetry. The EU institutions are much more effective in negative integration, namely in liberalising or market-making activities, than they are in positive legislation.

Rafał Riedel is a professor at Opole University (Poland) and Gastdozent at Chemnitz University of Technology (Germany). His research interests focus predominately on the Europeanisation of policies, polities and politics, political economy of European integration and related topics. His recent peer-reviewed articles have focused on the supranational monetary integration and its consequences as well as on Euroscepticism among the EU citizens. 


\section{References}

EC (2011), Directive 2011/24/EU of the European Union and the Council on the application of patients' rights in cross-border healthcare, Official Journal of the European Union, L 88/45.

_ (2013), Statement by Health Commissioner, Tonio Borg, on the entry into force of the Directive on Patients' Rights in Cross-border Healthcare, MEMO/13/918, Brussels: European Commission, 22.10.2013.

- (2015a), Evaluative Study on the Cross-border Healthcare Directive (2011/24/EU), Brussels: KPMG, Technopolis group, empirica GMBH.

— (2015b), Patients' Rights in Cross-border Healthcare in the European Union, Special Eurobarometer 425, Brussels: European Commission. Retrieved from http://ec.europa.eu/public_opinion/archives/ebs/ebs_425_sum_en.pdf [accessed 1 Aug 2016]

EPF (2015), Summary Report: Cross-Border Healthcare: Main Conclusions and Recommendations Arising from the EPF Series of Regional Conferences 2013-2014, Brussels: European Patients Forum.

Greer, S. L. (2011), 'The weakness of strong policies and the strength of weak policies: law, experimentalist governance, and supporting coalitions in European Union health care policy,' Regulation \& Governance, vol. 5, pp. 187-203. http://dx.doi.org/10.1111/j.1748-5991.2011.01107.x

Hartlev, M. (2010), 'Diversity and Harmonisation: Trends and Challenges in European Health Law,' European Journal of Health Law, vol. 17, pp. 37-50. http://dx.doi.org/10.1163/157180909X12604572349647

Hunt, J. \& Wallace, C. J. (2006), “Citizens' Rights to Receive Medical Treatment in Another EU Member State," Journal of Social Welfare \& Family Law, vol. 28, no. 2, pp. 217-228. http://dx.doi.org/10.1080/09649060600974325

Main, I. (2014), 'Medical Travels of Polish Female Migrants in Europe,' Sociologický časopis / Czech Sociological Review, vol. 50, no. 6, pp. 897-918. http://dx.doi.org/10.13060/00380288.2014.50.6.147

Peeters, M. (2012) "Free Movement of Patients: Directive 2011/24 on the Application of Patients' Rights in Cross-border Healthcare," European Journal of Health Law, vol. 19, pp. 29-60. http://dx.doi.org/10.1163/157180912X615158

Riedel, R. (2015), 'Europeizacja polityk publicznych' [Europanisation of public policies], Wrocławskie Studia Politologiczne, vol. 18, pp. 57-72.

— (2016), 'Europeizacja polityki ochrony zdrowia' [Europeanisation of health care policy], in R. Riedel (ed.) Europeizacja polityk publicznych $w$ Polsce [Europeanisation of public policies in Poland], Opole: Uniwersytet Opolski, pp. 33-44. 
Risse-Kappen, T. (2001), 'A European Identity? Europeanization and Evolution of the Nation-State Identities,' in M. G. Cowles, J. A. Caporaso \& T. Risse-Kappen (eds.) Transforming Europe: Europanization and Domestic Change, New York: Cornell University Press, pp. 198-216.

Sieveking, K. (2007), 'ECJ Rulings on Health Care Services and Their Effects on the Freedom of Cross-border Patient Mobility in the EU,' European Journal of Migration and Law, vol. 9, pp. 25-51. http://dx.doi.org/10.1163/138836407X179292

Toeller, A. E. (2010), 'Measuring and Comparing the Europeanization of National Legislation: A Research Note,' JCMS, vol. 48, no. 2, pp. 417-444.

Wallace, H. (1971), 'The Impact of the European Communities on National PolicyMaking,' Government and Opposition, vol. 6, no. 4, pp. 520-538. http://dx.doi.org/10.1111/j.1477-7053.1971.tb00827.x 